Editorial

\title{
Signal Analysis in Power Systems
}

\author{
Zbigniew Leonowicz * (D) and Michał Jasiński (D) \\ Faculty of Electrical Engineering, Wroclaw University of Science and Technology, 50370 Wroclaw, Poland; \\ michal.jasinski@pwr.edu.pl \\ * Correspondence: zbigniew.leonowicz@pwr.edu.pl
}

Citation: Leonowicz, Z.; Jasiński, M. Signal Analysis in Power Systems.

Energies 2021, 14, 7850.

https://doi.org/10.3390/en14237850

Received: 26 October 2021

Accepted: 29 October 2021

Published: 23 November 2021

Publisher's Note: MDPI stays neutral with regard to jurisdictional claims in published maps and institutional affiliations.
The idea of the call for the Special Issue "Signal Analysis in Power Systems" came from scholarly discussions about ever increasing complexity of the management and operation of today's power system. The analysis of power systems under various conditions represents one of the most important and complex tasks in modern electrical power engineering. Studies in this area are necessary to ensure that the reliability, efficiency, and stability of the power system is not adversely affected. This issue was devoted to reviews and applications of modern methods of signal processing used to analyze the operation of a power system and evaluate the performance of the system in all its aspects.

Smart Grid as an emerging research field of the current decade is the focus of this Issue. Monitoring capability with data integration, advanced analysis of support system control, enhanced power security and effective communication to meet the power demand, efficient energy consumption and minimum costs, as well as intelligent interaction between powergenerating and power-consuming devices depends on the selection and implementation of advanced signal analysis and processing techniques.

The positive response from the scientific community, reflected by the number and the quality of the contributions submitted, proves the significance of signal processing in examining various power system issues aiming at developing new paradigms of control and operation.

The Special Issue appeared as one of the most successful, collecting as much as over 10 citations per paper, in average (and peaking with 16 citations for [1]) - in just one year from the publication date of the last paper of the Issue.

The articles submitted, as well as the ones finally selected to be published, cover a broad range of thematic areas involving modern methods of signal processing, as convolutional neural networks for forecasting [1], sensitivity analysis based on scenarios of the operation of a virtual power plant [2], cluster analysis for power quality assessment [3,4] and the Delphi method for data management of restoration times of failures in power grid [5].

W provide hereby a brief review of the papers published, roughly classifying them according to the previously outlined thematic areas.

The paper [1] presents a Convolutional Neural Network $(\mathrm{CNN})$ approach consisting of different architectures, such as the regular CNN, multi-headed CNN, and CNN-LSTM (CNN-Long Short-Term Memory), which utilizes a sliding window data-level approach and other data pre-processing techniques to make accurate forecasts. This approach is to be applied in developing a stochastic energy management system for microgrids. Hence, a few contributions in this regard are as follows: A comprehensive review regarding weather forecasts, forecast errors, data sources, different methodologies used, and their importance in microgrid scheduling was conducted. The focus was kept on wind energy forecasts, solar generation, and load forecasts. A comparison between the performance of different possible structures of the neural network was carried out along with a multiple linear regression and an ARMA model. It was noticed that the CNN-simple and the CNN-LSTM methods perform best for all 1-hour, 1-day and 1-week predictions, with the CNN-LSTM providing better results on certain occasions. The ARMA model performed exceptionally 
for the 1-hour forecasts. The forecasting was carried out for 1 hour, 1 day, and 1 week with the function of electricity markets in mind. From accuracy metrics such as RMSE, MAE, and BIAS it can be concluded that the forecasting algorithms perform satisfactorily.

Article [2] presents calculations and power flow of a real virtual power plant (VPP), containing a fragment of a low and medium voltage distribution network. The VPP contains a hydropower plant (HPP), a photovoltaic system (PV) and energy storage system (ESS). The paper discusses the impact of the requirements on the maximum installed capacity of distributed energy resource (DER) systems and on the parameters of the energy storage unit. Investigations related to the influence of DER and ESS on power network conditions are presented.

One of the outcomes of the paper is the method of identifying the maximum power capacity of DER and ESS in accordance with technical network requirements. The applied method uses analytic calculations, as well as simulations using the Matlab environment, combined with real measurement data. The obtained results allow the influence of the operating conditions of particular DER and ESS on power flow and voltage conditions to be identified, the maximum power capacity of ESS intended for the planed VPP to be determined, as well as the influence of power control strategies implemented in a PV power plant on resources available for the planning and control of a VPP to be specified.

Two papers [3,4] focus on big-data processing in power systems, proposing the clustering methods applied to power quality analysis. Article [3] presents the application of data mining $(\mathrm{DM})$ to long-term power quality $(\mathrm{PQ})$ measurements. The Ward algorithm was selected as the cluster analysis (CA) technique to achieve an automatic division of the PQ measurement data. The presented analysis is conducted for the area-related approachall measurement point data are connected at an initial stage. The importance rate was proposed in order to indicate the parameters that have a high impact on the classification of the data. Important was the reduction in the size of the input database. The reduction in input data by $57 \%$ assured the classification with a $95 \%$ agreement when compared to the complete database classification.

Paper [4] presents the idea of a combined analysis of long-term power quality data using cluster analysis (CA) and global power quality indices (GPQIs). The aim of the proposed method is to obtain a solution for the automatic identification and assessment of different power quality condition levels that may be caused by different working conditions of an observed electrical power network (EPN). GPQIs are proposed to calculate a simplified assessment of the power quality condition of the data collected using CA. Two proposed global power quality indices are introduced for this purpose, one for 10 min aggregated data and the other for events-the aggregated data index (ADI) and the flagged data index (FDI), respectively. The obtained results indicate that the proposed method is a suitable tool for quick comparison between data collected in the identified clusters. Thus, the proposed method can also be considered for power quality assessment and is an alternative approach to the classic multi-parameter analysis of power quality data addressed to particular measurement points.

Paper [5] presents the analysis of power supply restoration time after failures occurring in power lines. It was found that the power supply restoration time depends on several constituents, such as the time necessary for obtaining information on failures, the time for information recognition, the time necessary to repair failures, and the time for connection harmonization. The Delphi method was used for determining the time necessary for obtaining information on failures as well as the time necessary for information recognition. The method of mathematical statistics was used to determine the repair time. The technical means of electrical network automation capable of the reduction in the power supply restoration time were also found.

Author Contributions: Writing—original draft preparation, Z.L.; writing—review and editing, M.J. All authors have read and agreed to the published version of the manuscript.

Funding: This research received no external funding. 
Institutional Review Board Statement: Not applicable.

Informed Consent Statement: Not applicable.

Data Availability Statement: Not applicable.

Acknowledgments: The editor of this Special Issue is grateful to the MDPI Publisher for the invitation to act as guest editor of this Special Issue. All authors are indebted to the editorial staff of "Energies" for the kind co-operation, patience and committed engagement.

Conflicts of Interest: The authors declare no conflict of interest.

\section{References}

1. Suresh, V.; Janik, P.; Rezmer, J.; Leonowicz, Z. Forecasting Solar PV Output Using Convolutional Neural Networks with a Sliding Window Algorithm. Energies 2020, 13, 723. [CrossRef]

2. Sikorski, T.; Jasiński, M.; Ropuszyńska-Surma, E.; Węglarz, M.; Kaczorowska, D.; Kostyla, P.; Leonowicz, Z.; Lis, R.; Rezmer, J.; Rojewski, W.; et al. A Case Study on Distributed Energy Resources and Energy-Storage Systems in a Virtual Power Plant Concept: Technical Aspects. Energies 2020, 13, 3086. [CrossRef]

3. Jasiński, M.; Sikorski, T.; Leonowicz, Z.; Borkowski, K.; Jasińska, E. The Application of Hierarchical Clustering to Power Quality Measurements in an Electrical Power Network with Distributed Generation. Energies 2020, 13, 2407. [CrossRef]

4. Jasiński, M.; Sikorski, T.; Kostyła, P.; Leonowicz, Z.; Borkowski, K. Combined Cluster Analysis and Global Power Quality Indices for the Qualitative Assessment of the Time-Varying Condition of Power Quality in an Electrical Power Network with Distributed Generation. Energies 2020, 13, 2050. [CrossRef]

5. Vinogradov, A.; Bolshev, V.; Vinogradova, A.; Jasiński, M.; Sikorski, T.; Leonowicz, Z.; Goňo, R.; Jasińska, E. Analysis of the Power Supply Restoration Time after Failures in Power Transmission Lines. Energies 2020, 13, 2736. [CrossRef] 